\title{
Carbon Nanotubes Inhibit the Hemolytic Activity of the Pore-Forming Toxin Pyolysin
}

\author{
Apraku David Donkor, Zhengding Su, Himadri S. Mandal, Xu Jin, and Xiaowu (Shirley) Tang ( $\square)$ \\ Department of Chemistry, University of Waterloo, Waterloo, ON N2L 3G1, Canada \\ Received: 19 November 2008 / Revised: 31 March 2009 / Accepted: 13 April 2009 \\ (CTsinghua University Press and Springer-Verlag 2009. This article is published with open access at Springerlink.com
}

\begin{abstract}
Functionalized carbon nanotubes have already demonstrated great biocompatibility and potential for drug delivery. We have synthesized acid oxidized and non-covalently PEGlyated single-walled carbon nanotubes (SWNTs), which were previously prepared for drug delivery purposes, and explored their potential for detoxification in the bloodstream. Our investigations of the binding of SWNTs to a pore-forming toxin pyolysin show that SWNTs prevented toxin-induced pore formation in the cell membrane of human red blood cells. Quantitative hemolysis assay and scanning electron microscopy were used to evaluate the inhibition of hemolytic activity of pyolysin. According to Raman spectroscopy data, human red blood cells, unlike HeLa cells, did not internalize oxidized SWNTs. Molecular modeling and circular dichroism measurements were used to predict the 3-D structure of pyolysin (domain 4) and its interaction with SWNTs. The tryptophan-rich hydrophobic motif in the membrane-binding domain of pyolysin, a common construct in a large family of cholesterol-dependent cytolysins, shows high affinity for SWNTs.
\end{abstract}

\section{KEYWORDS}

Single-walled carbon nanotubes(SWNT), pore-forming toxin, pyolysin, hemolytic activity, red blood cell, protein-nanotube interaction, detoxification

\section{Introduction}

Intoxication resulting from drug overdose, accidental exposure to toxic compounds, and bacterial toxins accounts for a significant number of deaths each year [1]. In many cases, antidotes are not available and detoxification procedures are largely based on general measures to clear the toxic agents out of the body. One example is hemodialysis (passing the blood through a bedside dialysis machine) for eliminating life-threatening toxins. A recently proposed strategy is to administer injectable nanocarriers as high capacity sinks for toxins in the blood [2]. Although substantial effort has been devoted to the development of nanoparticulate drug carriers, few reports of nanodetoxification systems can be found. Here, we report a pilot study of the development of carbon nanotube (CNT) carriers for biodetoxification. Functionalized single-walled carbon nanotubes (SWNTs) have been demonstrated to have great potential for targeted delivery of therapeutic compounds and diagnostic agents [3-6]. In general, systems for biodetoxification and drug delivery share similar characteristics (e.g., innocuousness, physical size, blood circulation time,

Address correspondence to tangxw@uwaterloo.ca 
loading capacity), but with distinctively different design goals and end points for performance evaluation. Instead of delivering therapeutic agents to targeted cells or tissues, biodetoxifiers commonly aim at rapid inactivation and clearance of toxic agents from the blood stream. In this study, we evaluate the potential of oxidized SWNTs as detoxifiers in the blood against pore-forming toxins (PFTs).

PFTs are mostly produced by pathogenic bacteria as water-soluble proteins destined to form pores in the lipid membranes of the host organism, which may lead directly or indirectly to the pathogenesis of acute and chronic diseases. Pore formation on cell membranes by PFTs is a major mechanism by which pathogenic bacteria cause host cell destruction and acquire nutrients from damaged cells essential for their survival [7]. In this study, we used pyolysin (PLO), an important virulence factor of Arcanobacterium pyogenes, as a model PFT [8]. PLO is a hemolysin and belongs to the family of cholesteroldependent cytolysins (CDCs), which comprises toxins produced by more than twenty species of gram-positive bacteria.

\section{Results and discussion}

\subsection{Preparation of SWNT aqueous solution}

Two types of water soluble SWNTs were prepared, namely, acid oxidized SWNTs (SWNT-OXs) and phospholipid polyethylene glycol (PL-PEG) suspended SWNTs (SWNT-PEGs) (see Methods section). SWNT-OX and SWNT-PEG have very similar physical dimensions, being $\sim 2 \mathrm{~nm}$ in diameter and less than $500 \mathrm{~nm}$ in length [3]. SWNT-OXs have sidewalls and ends decorated with carboxylic groups $(-\mathrm{COOH})$ and are therefore negatively charged at physiological $\mathrm{pH}$ [10]. SWNT-PEG is neutral and more hydrophilic due to the packing of long PEG chains with methoxy $\left(-\mathrm{OCH}_{3}\right)$ terminal groups on the SWNT sidewalls. The results presented in the main text are solely from SWNT-OX. Experimental results for SWNT-PEG are available in the Electronic Supplementary Material (ESM) which demonstrate the generality of water soluble SWNTs as detoxifiers regardless of differences in surface functionalization.

\subsection{Inhibition of hemolytic activity of PLO by SWNT-OX}

A quantitative microtiter plate hemolysis assay [11] was used to characterize the hemolytic activity of PLO with and without SWNT-OX. The decrease in turbidity, i.e., optical density at $650 \mathrm{~nm}\left(\mathrm{OD}_{650}\right)$, is directly correlated to lysis of human red blood cells (RBCs) [11]. The results were normalized and are shown in Fig. 1. For RBCs exposed to $20 \mathrm{nmol} / \mathrm{L}$ PLO (no SWNT-OX), $\mathrm{OD}_{650}$ declined rapidly to a baseline level, indicating complete lysis of RBCs in about 10 min. In the presence of SWNT-OX, hemolytic activity of PLO was inhibited in a concentration dependent fashion. With $10 \mathrm{nmol} / \mathrm{L}$ SWNT-OX in PBS buffer, $\mathrm{OD}_{650}$ remained almost constant over the period of observation $(2 \mathrm{~h})$, which suggests nearly complete inhibition of hemolysis (Fig. 1(a)). SWNT-OX alone did not cause any cell lysis (the data were identical to those from control RBCs). Furthermore, hemolysis assay was performed in $1 \times$ fetal bovine serum (FBS) (Fig. 1(b)), where serum proteins are present at concentrations four orders of magnitude higher than PLO (e.g., albumin $\sim 0.6 \mathrm{mmol} / \mathrm{L}$, immunoglobulin $\mathrm{G} \sim 0.23 \mathrm{mmol} / \mathrm{L})$. Compared to the results in PBS buffer, the inhibition effect was slightly milder, but still significant. At SWNT-OX concentrations equal to and above $20 \mathrm{nmol} / \mathrm{L}$, complete inhibition of hemolysis was again observed. Serum proteins by themselves did not alter the hemolytic activity of PLO.

Using scanning electron microscopy (SEM), we closely examined the cell membranes of RBCs exposed to PLO alone, SWNT-OX alone, and PLO in the presence of SWNT-OX. In the SEM images, 30-50 nm size pores formed by PLO in the absence of SWNT-OX were evident (Fig. 2(a)). In contrast, cell membranes of RBCs incubated with PLO $(20 \mathrm{nmol} / \mathrm{L})$ in the presence of SWNT-OX $(10 \mathrm{nmol} / \mathrm{L})$ in PBS buffer appeared smooth and intact (Fig. 2(b)), the same as those of control RBCs and RBCs exposed to SWNT-OX only (see ESM, Fig. S-1). The membranes of PLO-attacked cells can also be seen to be evidently rougher in optical images of whole RBCs (Fig. 2 insets). These observations confirmed that SWNTs prevented pore formation on cell membranes by 


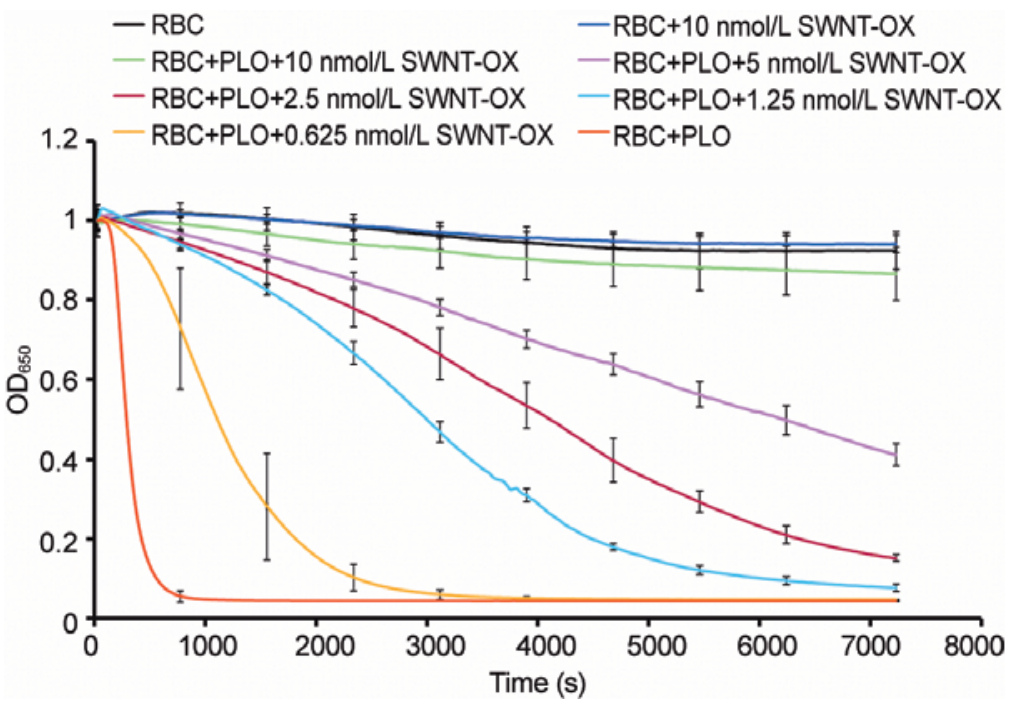

(a)

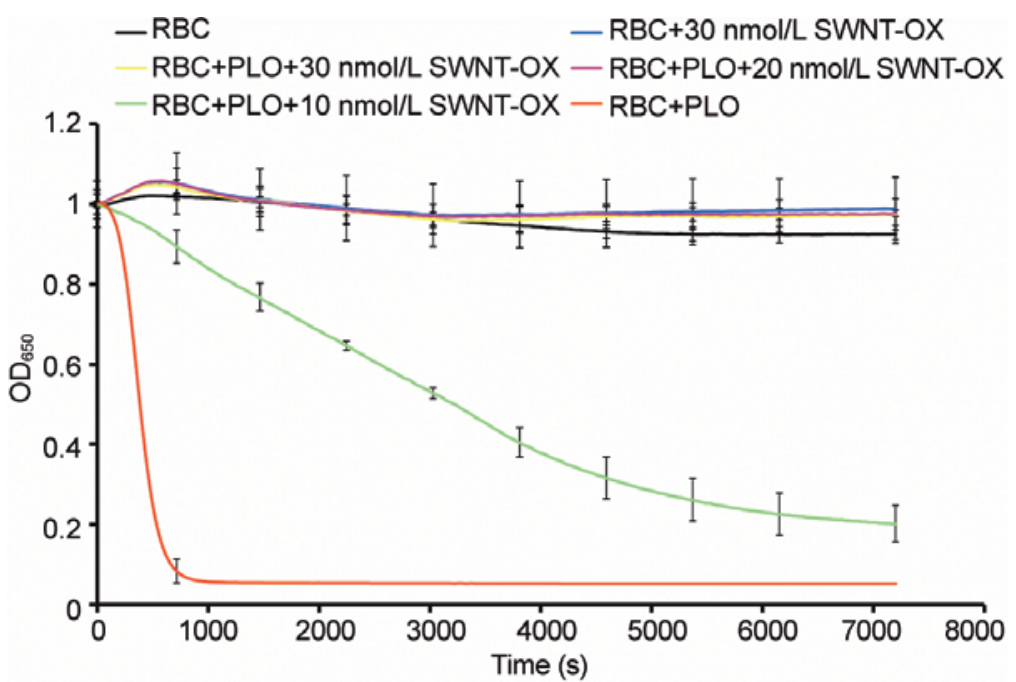

(b)

Figure 1 Microtitre hemolysis assay illustrating the effect of different concentrations of SWNT-OX on PLO activity in (a) $1 \times$ PBS buffer ( $\mathrm{pH}$ 7.2) and (b) serum. Hemolysis of human RBCs was measured by reading the optical density at $650 \mathrm{~nm}$

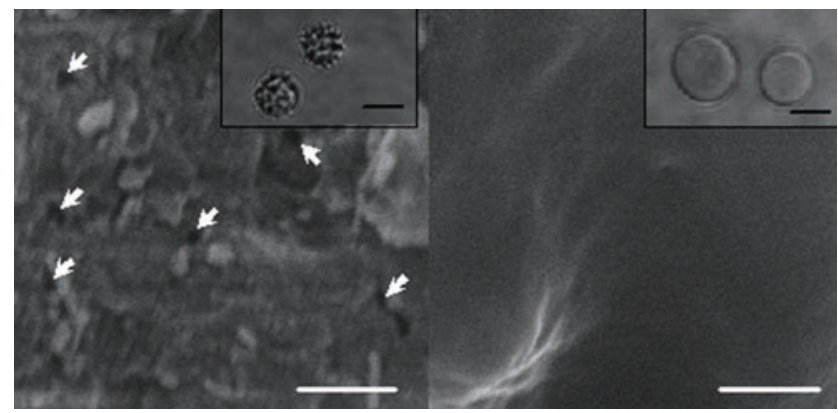

(a)

(b)

Figure 2 SEM images of the cell membranes of human RBCs exposed to (a) 20 $\mathrm{nmol} / \mathrm{L}$ PLO alone and (b) $20 \mathrm{nmol} / \mathrm{L}$ PLO plus $10 \mathrm{nmol} / \mathrm{L}$ SWNT-OX in PBS buffer. The arrows indicate the pores formed by PLO. Scale bars $500 \mathrm{~nm}$. Insets are optical images of corresponding whole RBCs (scale bars $5 \mu \mathrm{m}$ ) inhibiting the hemolytic activity of PLO.

\subsection{Cellular uptake of SWNT-OX by RBCs}

We further studied cellular uptake of SWNT-OX by RBCs using Raman spectroscopy/imaging, and compared it with that by HeLa cells, a cell line which has been demonstrated in several literature reports to internalize SWNTs efficiently [12]. HeLa cells and RBCs were incubated in SWNT-OX solutions under the same conditions (70 nmol/L SWNT-OX for $2 \mathrm{~h}$ at $37{ }^{\circ} \mathrm{C}$ ). The strong Raman band at $1590-1600 \mathrm{~cm}^{-}$ ${ }^{1}$ called the tangential mode (or G band), which is caused by stretching along $C$ $-\mathrm{C}$ bonds of graphene, was used as the signature to detect and map the presence of SWNT-OX inside cells or attached to cell membranes [4, 13]. Figure 3(a) shows a Raman image of a single HeLa cell, in which black color indicates locations with high $G$ band intensity. Figure 3(b) shows a typical Raman spectrum acquired in the middle of the cell region, which demonstrates clearly the uptake of SWNTs by HeLa cells. In contrast, no SWNT was observed inside or attached to RBCs (Fig. 3(c)), even though abundant SWNT-OX were present in the solution in which the RBCs were incubated (Fig. 3(c) inset). This result suggests that SWNT-OXs translocated into HeLa cells but not into RBCs, at least not at the levels observed for HeLa cells. RBCs are known to have lower endocytic activities than cancerous cell lines like HeLa, which could contribute to the lower or no cellular uptake of SWNT-OX by RBCs, since endocytosis is suggested to be one of the main trans-membrane mechanisms for SWNTs [14]. 


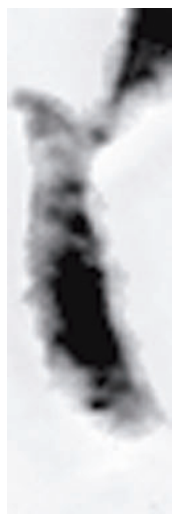

(a)

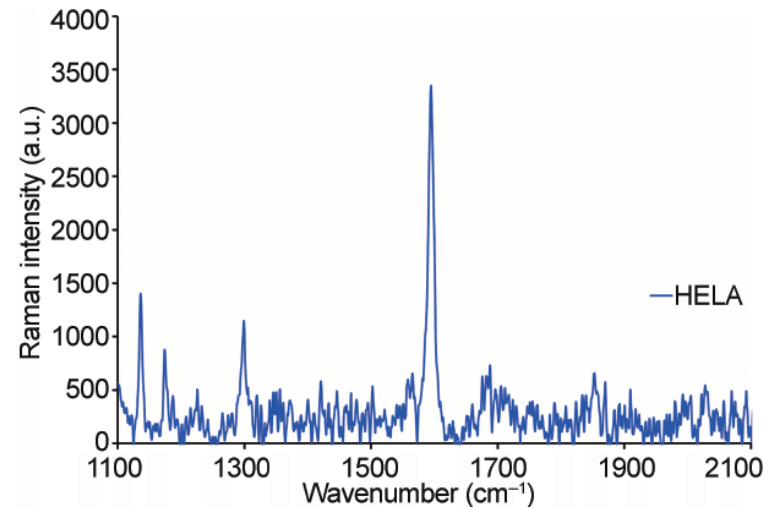

(b)

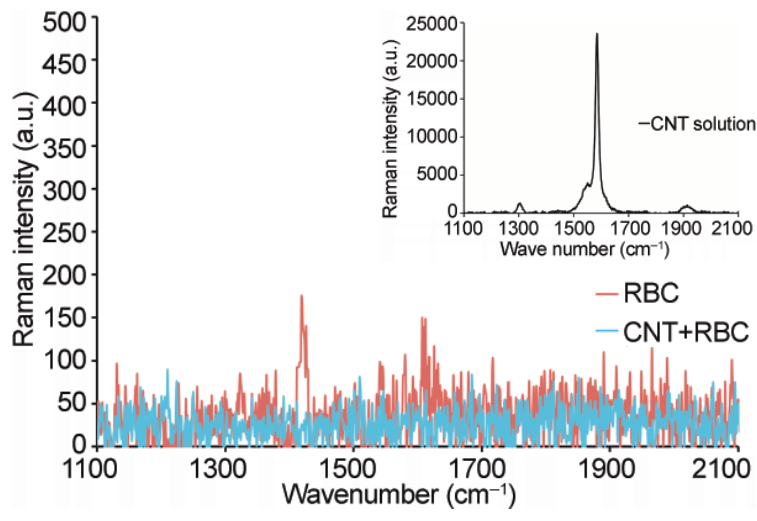

(c)

Figure 3 Raman spectroscopy/imaging studies of cellular uptake of SWNT-OX: (a) Raman image of a HeLa cell (color code: black, high G band intensity; scale bar $10 \mu \mathrm{m}$ ); (b) a typical Raman spectrum taken in the middle of the HeLa cell shown in (a); (c) Raman spectra taken from control human RBCS and RBCS after exposure to SWNT-OX under the same conditions as HeLa cells. (Inset) Raman spectrum taken from SWNT-OX solution in which human RBCs were incubated

\subsection{Interactions of PLO with SWNT}

PLO, in common with other CDCs, is secreted as soluble monomeric molecules. Upon binding to a cell membrane, PLO oligomerizes to form oligomeric pre-pores, which then insert into the lipid bilayer to form the final trans-membrane pores [15]. PLO consists of four domains. Domain 4 (PLO-D4), which contains the highly conserved tryptophan (Trp)-rich undecapeptide sequence, is believed to mediate the binding of PLO and some other CDCs to cholesterolcontaining membranes and has been shown to insert into cell membranes [16]. We suspected that the strong affinity of PLO-D4 for SWNT-OX could inactivate $\mathrm{PLO}$ in the solution phase and prevent PLO binding to the cell membrane. To test this hypothesis, we carried out molecular modeling and circular dichroism (CD) measurements.

The predicted 3-D conformation of PLO-D4 (Fig. $4(\mathrm{a}))$ indicates that the protein has a $\beta$-sheet-bundle structure. The CD spectrum of PLO-D4 in the "farUV" region (190-250 nm) also consistently suggested the abundant presence of $\beta$-sheet structures (Fig. $4(\mathrm{~b})$ ). It is noteworthy that PLO-D4 has a total of nine Trp residues (positions 6, 8, 17, 35, 39, 71, 74, 75, and 101). Six of them are located on one end of the $\beta$-sheet-bundle where the protein surface is highly hydrophobic. Based on the 3-D homology model, Trp6, Trp8, Trp39, Trp71, Trp74, and Trp75 compose or are very close to a hydrophobic aromatic patch on the protein surface (Fig. 4(c)). It has been reported that aromatic molecules can interact strongly with CNTs [17]. Previous research has also shown the importance of Trp residues for peptide-nanotube interactions [18 -20]. Therefore, a pristine $(10,10)$ SWNT (which does not contain side groups or defects) was manually docked into this area of PLO-D4 using Insight II to create a preliminary working model. This visually docked structure was then imported into the docking software program Molegro Virtual Docker. The default cavity detection algorithm of the program was utilized and a cavity created between the docked nanotube and the protein was used as the focus for the generation of a $25 \AA$ radius binding site docking search with the following 17 residues in close proximity to the nanotube marked as flexible for the docking process (Trp6, Trp8, Thr67, Gly68, Leu69, Ala70, Trp71, Asp72, Trp74, Trp75, Thr76, Asn79, Lys80, Thr97, Leu98, Asn99, and Pro100) (see ESM, Fig. S-2). Default conditions were used in the docking calculations and MolDock Score (Grid) was used as the scoring function for ranking the various docked poses of the nanotube with the protein model. The top 10 poses (lowest energies) were kept for analysis. The lowest energy docked structure from these calculations is shown in Fig. 4(d). This simulated interaction between PLO-D4 and SWNT supports the CD results for the protein titrated by SWNT-OX (Fig. $4(\mathrm{~b}))$, suggesting that the secondary structure of the protein is unaffected by binding to the nanotube. It is 
likely that the pre-existence of a hydrophobic aromatic patch on the surface of PLO-D4 forms a native binding site for docking SWNT. High affinity binding of PLO-D4 on SWNT-OX was also visualized using atomic force microscopy (Fig. 5).

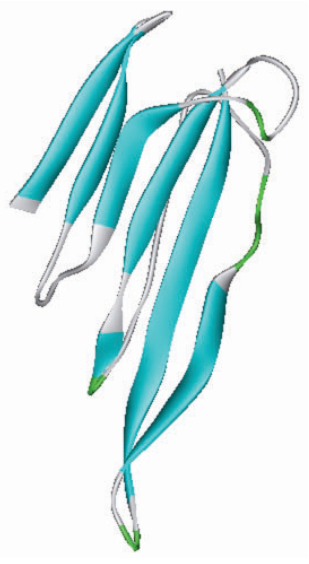

(a)

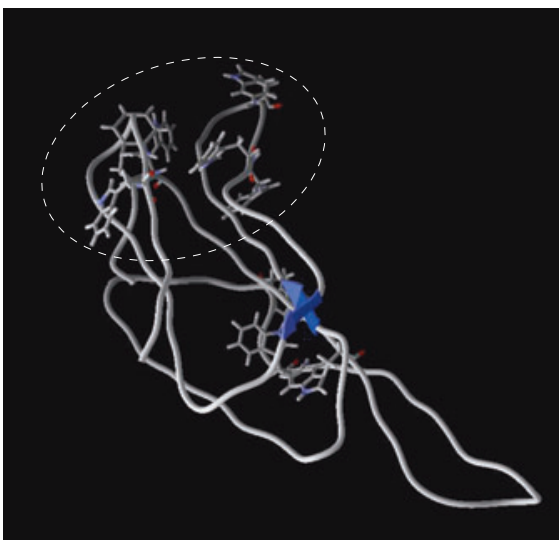

(c)

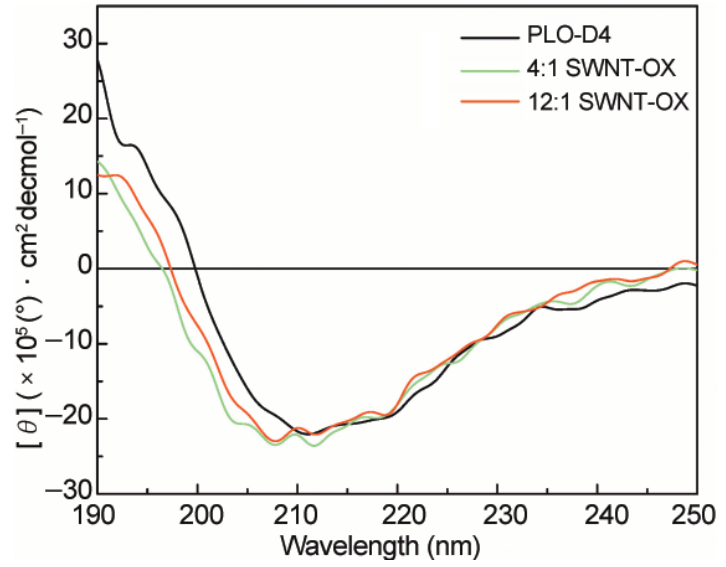

(b)

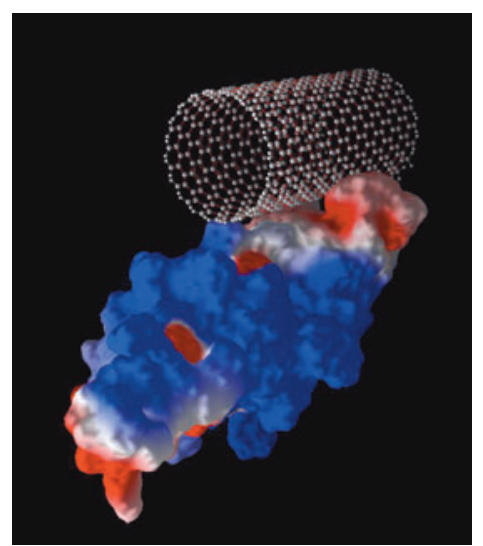

(d)

Figure 4 Three-dimensional structure of PLO-D4 and its interaction with SWNT: (a) the homology model of the protein suggests a $\beta$-sheet-bundle structure; (b) CD spectra of PLO-D4 and mixtures of PLO-D4 and SWNT-OX with a molar ratio of 4:1 and 12:1; (c) stick model of PLO-D4 showing a hydrophobic aromatic patch on one end of the bundle (in the dashed circle) rich in Trp residues; (d) structure of PLO-D4 in the complex with the nanotube in surface view. (Color key: red, hydrophobic sites; blue, hydrophilic sites)

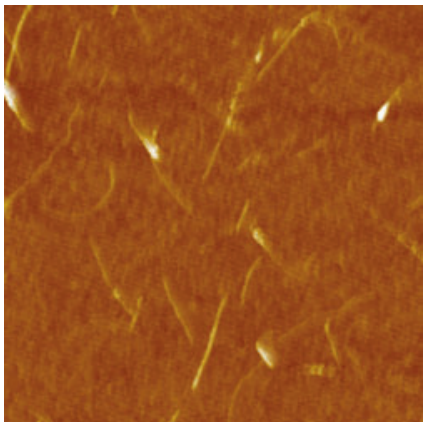

(a)

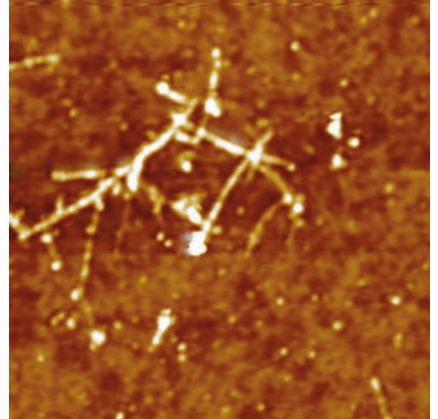

(b)

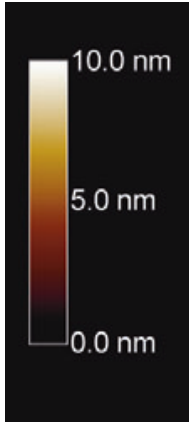

Figure 5 AFM images of SWNT-OX before (a) and after (b) PLO-D4 adsorption. Scale bars $500 \mathrm{~nm}$
The effects of side groups and surfactants on the PLO/SWNT binding were not considered in the molecular simulations, since surface coverages of surfactants or functional groups on both SWNT-OX and SWNTPEG are fairly low. According to the acid oxidation conditions, there are about seven $-\mathrm{COOH}$ groups per thousand carbon atoms decorating the SWNT-OX sidewall [21]. In the case of SWNT-PEG, the percentage of surface area covered by PL-PEG is estimated to be about $10 \%$ [22]. Therefore, the intrinsic (non-functionalized) region of SWNT sidewall is anticipated to be dominant in interacting with proteins and peptides.

\section{Methods}

\subsection{Preparation of PLO and its domain 4}

Cultures (100 mL) of E. coli BL21 carrying the pTrcHis B plasmid with wild type PLO [23] were grown in Luria-Bertani (LB) broth (Bioshop, Burlington, Ontario) with ampicillin $(100 \mu \mathrm{g} / \mathrm{mL})$ at $37^{\circ} \mathrm{C}$. Once the $\mathrm{OD}_{650}$ reached 1 , protein expression was induced with 1.0 $\mathrm{mmol} / \mathrm{L}$ isopropylthiogalactoside (IPTG), and incubation continued for another $3 \mathrm{~h}$. Flasks of cells were then placed on an orbital shaker (150 rpm) overnight at $25{ }^{\circ} \mathrm{C}$. Cells were harvested by centrifugation at 500 $g$ for $10 \mathrm{~min}$ and the cell pellet was resuspended in column binding buffer $(20 \mathrm{mmol} / \mathrm{L}$ Tris $/ \mathrm{HCl}, 150 \mathrm{mmol} / \mathrm{L}$ $\mathrm{NaCl}, 10 \mathrm{mmol} / \mathrm{L}$ imidazole, $\mathrm{pH}$ 8.0). The cells were lysed using an emulsifier (Avestin Emulsiflex-C5) at 17,500 psi and the insoluble material was removed by centrifugation at

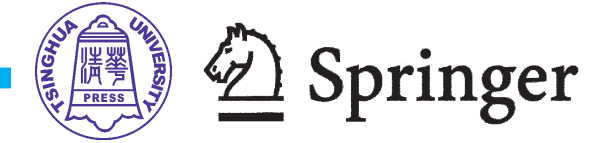


$12,000 \mathrm{~g}$ for $30 \mathrm{~min}$. Histidine-tagged PLO was purified from the soluble fraction by metal-chelating chromatography on Ni-nitrilotriacetic acid (NTA) agarose (Novagen, Oakville, Ontario), using a linear gradient of imidazole $(10-450 \mathrm{mmol} / \mathrm{L})$ in binding buffer for elution. The same protocol was followed for the purification of PLO-D4.

\subsection{Preparation of water soluble SWNTs}

Two types of water soluble SWNTs were produced, namely, acid oxidized (SWNT-OX) and PL-PEG suspended (SWNT-PEG). In both cases, raw HipCo tubes (Carbon Nanotechnologies) were used as the starting material. A widely used method of acid oxidation was used to make SWNT-OX. The detailed protocol has been reported in a previous study [9]. To make SWNT-PEG, SWNT powder was sonicated in 1 mg/mL PL-PEG (molecular mass 2805 g/mol, Avanti Polar Lipids) in deionized water for $1 \mathrm{~h}$ and then centrifuged $(22,000 g, 6 \mathrm{~h})$ to remove larger insoluble impurities. The physical dimensions and purity of SWNT-OX and SWNT-PEG were characterized using atomic force microscopy (AFM), scanning electron microscopy (SEM), and energy-dispersive analytical X-ray (EDAX) spectrometry. An AFM image of SWNT-OXs is shown in Fig. 5(a). Results using other characterization methods were reported previously [9], and are therefore not presented here. UV-vis-NIR spectroscopy (with an extinction coefficient of $0.0079(\mathrm{nmol} / \mathrm{L})^{-1} \cdot \mathrm{cm}^{-1}$ at $808 \mathrm{~nm}$ ) was used to determine the concentration of SWNTs in aqueous solutions [24].

\subsection{Hemolysis assay}

For the hemolysis assay, $400 \mu \mathrm{L}$ of pelleted human erythrocytes (Cederlane) were washed four times in $1 \times$ PBS buffer $(137 \mathrm{mmol} / \mathrm{L} \mathrm{NaCl}, 2.7 \mathrm{mmol} / \mathrm{L}$ $\mathrm{KCl}, 10 \mathrm{mmol} / \mathrm{L}$ phosphate buffer, $\mathrm{pH} 7.3$ ) by centrifugation. The erythrocytes (RBCs) were then resuspended in PBS buffer to $1 \%(\mathrm{v} / \mathrm{v})$ [11]. Equal numbers of RBCs in PBS buffer were transferred into wells of a 96-well plate containing PLO and different concentrations of SWNTs either in $1 \times$ PBS buffer or in $1 \times$ FBS. The final concentration of PLO was kept the same $(20 \mathrm{nmol} / \mathrm{L})$ in all wells, except in the control with RBCs alone. Hemolytic activity was measured by the decrease in turbidity $\left(\mathrm{OD}_{650}\right)$ using a 96-well plate reader (Specramax 190, Molecular Devices) at room temperature over a period of $2 \mathrm{~h}$. Hemolytic titration was performed for SWNTs alone with RBCs, and for SWNTs plus PLO with RBCs. As a control, the turbidities of RBCs alone (no SWNTs, no PLO) and RBCs with wild type PLO (no SWNTs) were measured. The error bars indicate the standard deviations of five replicates per treatment.

\subsection{SEM sample preparation}

High-resolution SEM (LEO FESEM 1530, Carl Zeiss SMT Inc.) was used to examine the cell membranes of human RBCs incubated in (1) $20 \mathrm{nmol} / \mathrm{L}$ PLO alone for $5 \mathrm{~min}$, (2) $20 \mathrm{nmol} / \mathrm{L}$ PLO plus $10 \mathrm{nmol} / \mathrm{L}$ SWNT-OX for $2 \mathrm{~h}$, and (3) incubated in $10 \mathrm{nmol} / \mathrm{L}$ SWNT-OX alone for $2 \mathrm{~h}$. Incubation was carried out at room temperature. Control RBCs which had not been exposed to PLO or SWNTs were also imaged. Before fixation, the cells were washed four times with $1 \times$ PBS buffer $(\mathrm{pH}$ 7.2) through filtration to remove free or loosely bound PLO or SWNTs. Finally, a standard SEM sample preparation procedure was followed [25].

\subsection{Raman spectroscopy/imaging}

Raman spectra were recorded with a LabRam HR system (HORIBA Jobin Yvon) equipped with an upright microscope and a piezo sample stage. Both HeLa cells and RBCs were incubated in $1 \times$ PBS buffer with an elevated SWNT-OX concentration $(70 \mathrm{nmol} / \mathrm{L})$ for $2 \mathrm{~h}$ at $37^{\circ} \mathrm{C}$. RBCs were then washed with $1 \times$ PBS buffer and collected using centrifugation. The pellet of RBCs was then deposited and dried on a microscope slide. HeLa cells were directly cultured on a microscope slide and washed on the substrate with $1 \times$ PBS buffer at least four times. The Raman spectra were baseline corrected to remove the broad background Raman signal from cells and fixatives. For Raman imaging, cells were fixed following a standard procedure and the piezo stage was programmed to raster scan a $30 \mu \mathrm{m} \times 90 \mu \mathrm{m}$ region with $1 \mu \mathrm{m}$ step size. 


\subsection{Circular dichroism measurements}

Circular dichroism was performed on free and SWNTbound PLO-D4 using a Jasco J-715 spectropolarimeter (Easton, MD). Proteins were dissolved in $5 \mathrm{mmol} / \mathrm{L}$ $\mathrm{K}_{2} \mathrm{HPO}_{4}$ buffer ( $\mathrm{pH}$ 7.2) at a concentration of 0.27 $\mu \mathrm{mol} / \mathrm{L}$. The spectra were measured between 190 and $250 \mathrm{~nm}$ as the average of 15 successive scans with a bandwidth of $1.0 \mathrm{~nm}$ and a scan speed of $20 \mathrm{~nm} / \mathrm{min}$. SWNT-OX and PLO-D4 were mixed and left at room temperature for $2 \mathrm{~h}$ to allow sufficient binding to take place. The molar ratios of PLO-D4 to SWNT-OX were 12:1 or 4:1. Note that we observed significant slowing down of PLO activity at those molar ratios in our hemolysis assay. We did not observe a CD signal from SWNT-OX alone.

\subsection{Molecular modeling}

The homology model of PLO-D4 was obtained using ESyPred3D program [26], and verified through energy minimization using the Discover_3 module in Accelrys Insight II software (Version 2005, San Diego, CA). An AMBER force field, AMBER-99, was adopted, which was converted by the AmberFFC program [27]. The coordinates of SWNT presented in PDB format were generated with the Accelrys MS Studio program (San Diego, CA). The docking software program Molegro Virtual Docker [28] (MVD 2008.3.0.0; Molegro ApS, Denmark) was used to simulate the interaction between protein and nanotube.

\subsection{Atomic force microscopy (AFM)}

To study PLO-D4 and SWNT-OX binding, they were mixed at a molar ratio of 10:1 in PBS for $2 \mathrm{~h}$. The solution was then filtered through a $100 \mathrm{kDa}$ molecular weight cut-off (MWCO) membrane to remove free and loosely bound PLO-D4 (15 kDa). The residue containing SWNT-OXs possibly loaded with PLO-D4 was then deposited on a silicon substrate and imaged using a Multimode III a Veeco atomic force microscope. For comparison, as-prepared SWNT-OXs were imaged at the same resolution.

\section{Conclusions}

Oxidized SWNTs have been shown to inhibit the activity of a pore-forming toxin, PLO. At a 1:1 molar ratio of SWNT-OX:PLO in serum,SWNT-OXs were able to completely inactivate trace amounts of PLO $(20 \mathrm{nmol} / \mathrm{L})$, which indicates that SWNT-OXs can act as a selective toxin sink. Molecular modeling results suggested that the Trp-rich hydrophobic domain of PLO has a high affinity for SWNTs in general [29], since the calculations did not involve specific functional side groups or surfactants. Besides SWNTOX, a different type of water soluble SWNT, SWNTPEG, was also tested (data available in the ESM, Fig. S-3) in order to demonstrate the generality of SWNTs as an antidote to PLO. Tight binding of SWNTs to domain 4 of PLO is believed to block the anchoring of PLO onto a cell membrane. It is anticipated that SWNTs will be able to function as a generic antidote to a wide variety of PFTs, since they have similar Trp residue-rich domains for lipid membrane binding. We did not observe any toxic effect of SWNT-OX and SWNT-PEG on human RBCs in this study. Furthermore, the Raman spectroscopic data indicated that it is very unlikely that SWNT-OX entered RBCs. No uptaken SWNT-OX was observed in RBCs even after exposure to a relatively high concentration of SWNT-OX solution.

Future challenges in designing CNT detoxification and drug delivery systems still remain. The blood circulation half-lives of current CNT carriers range from 0.5 to $3.5 \mathrm{~h}$ in mice $[3,6,30]$, which are significantly shorter than that of PEG-grafted liposomes (12-20 h in rats or mice, and $40-60 \mathrm{~h}$ in humans) [31]. While some reports have shown renal excretion of certain CNTs [6, 32, 33], there have also been others showing accumulation in organs such as liver, spleen, and kidney [3, 30, 34]. Although no acute or short-mid term (up to four months) cytotoxic effects on the organs or the test subjects have been reported so far, the long term toxicity and immunogenicity of CNT carriers are unclear. Systematic investigation of the blood compatibility of CNT carriers remains to be completed. Finally, in order to use molecular modeling as an effective design tool, it will be desirable to include functional groups and surfactants in future CNT models, as well as to include mid-long distance interactions. 


\section{Acknowledgements}

The authors would like to thank D. Weber for assistance with SEM measurements, Lisa Pokrajac and Dr. M. Palmer for PLO production and purification, and Dr. J. F. Honek for assistance in molecular modeling. This work was supported by Dr. Tang's startup fund from University of Waterloo and by grants from the Natural Science and Engineering Research Council (NSERC) of Canada.

Electronic Supplementary Material: Supplementary material is available in the online version of this article at http://dx.doi.org/10.1007/s12274-009-9049-0 and is accessible free of charge.

\section{References}

[1] Mokhlesi, B.; Leiken, J. B.; Murray, P.; Corbridge, T. C. Adult toxicology in critical care Part I: General approach to the intoxicated patient. CHEST 2003, 123, 577-592.

[2] Leroux, J. C. Injectable nanocarriers for biodetoxification. Nat. Nanotechol. 2007, 2, 679-684.

[3] Liu, Z.; Cai, W. B.; He, L. N.; Nakayama, N.; Chen, K.; Sun, X. M.; Chen, X. Y.; Dai, H. J. In vivo biodistribution and highly efficient tumor targeting of carbon nanotubes in mice. Nat. Nanotechnol. 2007, 2, 47-52.

[4] Heller, A. D.; Baik, S.; Eurell, E. T.; Strano, S. M. Singlewalled carbon nanotube spectroscopy in live cells: Towards long-term labels and optical sensors. Adv. Mater. 2005, 17, 2793-2799.

[5] Kam, N. W. S.; Jessop, T. C.; Wender, P. A.; Dai, H. J. Nanotube molecular transporters: Internalization of carbon nanotube-protein conjugates into mammalian cells. J. Am. Chem. Soc. 2004, 126, 6850-6851.

[6] Singh, R.; Pantarotto, D.; Lacerda, L.; Pastorin, G.; Klumpp, C.; Prato, M.; Bianco, A.; Kostarelos, K. Tissue biodistribution and blood clearance rates of intravenously administered carbon nanotube radiotracers. P. Natl. Acad. Sci. USA 2006, 103, 3357-3362.

[7] van der Goot, F. G. Pore-Forming Toxins; Springer: New York, NY., 2001

[8] Billington, J. S.; Jost, B. H.; Cuevas, W. A.; Bright, K. R.; Songer, J. G. The Arcanobacterium (Actinomyces) pyogenes hemolysin, pyolysin, is a novel member of the thiol-activated cytolysin family. J. Bacteriol. 1997, 179,
6100-6106.

[9] Ghafari, P.; St-Denis, C. H.; Power, M. E.; Jin, X.; Tsou, V.; Mandal, H. S.; Bols, N. C.; Tang, X. W. Impact of carbon nanotubes on the ingestion and digestion of bacteria by ciliated protozoa. Nat. Nanotechol. 2008, 3, 347-351.

[10] Li, Y. H.; Wang, S. G.; Luan, Z. K.; Ding, J.; Xu, C. L.; Wu, D. H. Adsorption of cadmium(II) from aqueous solution by surface oxidized carbon nanotubes. Carbon 2003, 41, 1057-1062.

[11] Lang, S.; Palmer, M. Characterization of Streptococcus agalactiae CAMP factor as a pore forming toxin. J. Biol. Chem. 2003, 278, 38167-38173.

[12] Kam, N.W.S.; Dai, H. J. Single walled carbon nanotubes for transport and delivery of biological cargos. Physica Status Solid B 2006, 243, 3561-3566.

[13] Liu, Z.; Winters, M.; Holodniy, M.; Dai, H. J. siRNA delivery into human $T$ cells and primary cells with carbon nanotube transporters. Angew. Chem. Int. Ed. 2007, 46, 2023-2027.

[14] Kam, N.W.S.; Liu, Z.; Dai, H. J. Carbon nanotubes as intracellular transporters for proteins and DNA: An investigation of the uptake mechanism and pathway. Angew. Chem. Int. Ed. 2006, 45, 577-581.

[15] Palmer M. The family of thiol-activated, cholesterol binding cytolysins. Toxicon 2001, 39, 1681-1689.

[16] Tweten, R. K. Cholesterol dependent cytolysins, a family of versatile pore forming toxins. Infect. Immun. 2005, 73, 6199-6209.

[17] Zorbas, V.; Smith, A. L.; Xie, H.; Ortiz-Acevedo, A.; Dalton, A. B.; Dieckmann, G. R.; Draper, R. K.; Baughman, R. H.; Musselman, I. H. Importance of aromatic content for peptide/single-walled carbon nanotube interactions. J. Am. Chem. Soc. 2005, 127, 12323-12328.

[18] Su, Z. D.; Leung, T.; Honek, J. F. Conformational selectivity of peptides for single-walled carbon nanotubes. J. Phys. Chem. B 2006, 110, 23623-23627.

[19] Su, Z. D.; Mui, K.; Daub, E.; Leung, T.; Honek, J. Singlewalled carbon nanotube binding peptides: Probing tryptophan's importance by unnatural amino acid substitution. J. Phys. Chem. B 2007, 111, 14411-14417.

[20] Wang, S. Q.; Humphreys, E. S.; Chung, S. Y.; Delduco, D. F.; Lustig, S. R.; Wang, H.; Parker, K. N.; Rizzo, N. W.; Subramoney, S.; Chiang, Y. M. Jagota, A. Peptides with selective affinity for carbon nanotubes. Nat. Mater. 2003, 2, 196-200. 
[21] Chen, S. M.; Shen, W. M.; Wu, G. Z.; Chen, D.; Jiang, M. A new approach to the functionalization of single-walled carbon nanotubes with both alkyl and carboxyl groups. Chem. Phys. Lett. 2005, 402, 312-317.

[22] Liu, Z.; Sun, X. M.; Nakayama-Ratchford, N.; Dai, H. J. Supramolecular chemistry on water-soluble carbon nanotubes for drug loading and delivery. ACS Nano 2007, 1, 50-56.

[23] Billington, S. J.; Songer, J. G.; Jost, B. H. The variant undecapeptide sequence of the arcanobacterium pyogenes haemolysin, pyolysin, is required for full cytolytic activity. Microbiology, 2002, 148, 3947-3954.

[24] Kam, N. W. S.; O'Connell, M.; Wisdom, J. A.; Dai, H. J. Carbon nanotubes as multifunctional biological transporters and near-infrared agents for selective cancer cell destruction. P. Natl. Acad. Sci. USA 2005, 102, 11600-11605.

[25] Benga, Gh.; Porutiu, D.; Ghirn, I.; Kuchel, W. P.; Gallagher, H. C.; Cox, C. G. Scanning electron microscopy of red blood cells from eleven species of marsupial. Comparative Haematol. Intern. 1992, 2, 227 230.

[26] Lambert, C.; Leonard, N.; De Bolle,X.; Depiereux, E. ESyPred3D: Prediction of proteins 3D structures. Bioinformatics 2002, 18, 1250-1256.

[27] Dejoux, A.; Cieplax, P.; Hannick, N.; Moyna, G.; Dupradeau, F. Y. AmberFFC, a flexible program to convert AMBER and GLYCAM force fields for use with commercial molecular modeling packages. J. Mol.
Model. 2001, 7, 422-432.

[28] Thomsen, R.; Christensen, M. H. MolDock: A new technique for high-accuracy molecular docking. J. Med. Chem. 2006, 49, 3315-3321.

[29] Xie, H.; Becraft, E. J.; Baughman, R. H.; Dalton, A. B.; Dieckmann, G. R. Ranking the affinity of aromatic residues for carbon nanotubes by using designed surfactant peptides. J. Pept. Sci. 2008, 14, 139-151.

[30] Cherukuri, P.; Gannon, C. J.; Leeuw, T. K.; Schmidt, H. K.; Smalley, R. E.; Curley, S. A.; Weisman, R. B. Mammalian pharmacokinetics of carbon nanotubes using intrinsic near-infrared fluorescence. P. Natl. Acad. Sci. USA, 2006, 103, 18882-18886.

[31] Woodle, M. C. Controlling liposome blood clearance by surface-grafted polymers. Adv. Drug. Deliver. Rev. 1998, 32, 139-152.

[32] Lacerda, L.; Herrero, M. A.; Venner, K.; Bianco, A.; Prato, M.; Kostarelos, K. Carbon nanotube shape and individualization critical for renal excretion. Small 2008, 4, 1130-1132.

[33] Wang, H. F.; Wang, J.; Deng, X. Y.; Sun, H. F.; Shi, Z. J.; Gu, Z. N.; Liu, Y. F.; Zhao, Y. L. Biodistribution of single-walled carbon nanotubes in mice. J. Nanosci. Nanotechnol. 2004, 4, 1019-1024.

[34] Schipper, M. L.; Nakayama-Ratchford, N.; Davis, C. R.; Kam, N. W. S.; Chu, P.; Liu, Z.; Sun, X. M.; Dai, H. J.; Gambhir, S. S. A pilot toxicology study of single-walled carbon nanotubes in a small sample of mice. Nat. Nanotechol. 2008, 3, 216-221. 